\title{
Validación de una escala de mediaciones culturales en el contexto de proyectos socioculturales comunitarios
}

\author{
Elier González-Martínez* (i) \\ Belkis Rojas Hernández** (i)
}

\section{Resumen}

La presencia de proyectos socioculturales comunitarios que tienen en el arte su motor impulsor ha diversificado disímiles contextos urbanos y rurales. El objetivo de esta investigación es la creación y validación de una escala que permita analizar y comprender las formas de acción y manifestación de las mediaciones culturales en las comunidades. El instrumento, compuesto por cinco dimensiones - estética, artística, participativa, axiológica y anclaje territorial - responde a un concepto de mediaciones culturales manifiestas en la construcción, reproducción e intercambio simbólico producido entre los factores culturales, los dispositivos artísticos, el territorio y el público participante de un proyecto sociocultural comunitario. Se utilizó un enfoque mixto en la investigación, donde se triangularon los resultados de varios focus groups, rondas de expertos y pruebas estadísticas que demuestran la validez y confiabilidad del instrumento. Los ítems propuestos para cada dimensión resultaron del análisis literario, de diferentes focus groups con especialistas en la temática y de la validación de expertos a través del método Delphi. El cuestionario se aplicó a 268 participantes de diversos proyectos socioculturales. El índice de consistencia interna mostró un coeficiente de 0,845 , mientras que en el análisis factorial exploratorio se confirmaron las dimensiones creadas a través de las comunalidades surgidas. En el análisis factorial confirmatorio se evidenció la correlación entre todas estas dimensiones. En las subescalas, los Alpha de Cronbach fueron satisfactorios, así como la correlación entre ítems.

Palabras clave: mediaciones culturales, escala, proyectos socioculturales, arte.

* Universidad Politécnica Salesiana de Ecuador, Guayaquil, Ecuador.

** Universidad de Pinar del Río, Pinar del Río, Cuba. 


\title{
Validation of a scale of cultural mediations in the context of community sociocultural projects
}

\begin{abstract}
The presence of community sociocultural projects that have art as their driving force has diversified dissimilar urban and rural contexts. This research is aimed at the creation and validation of a scale that could allow us to analyze and understand the forms of action and manifestation of cultural mediations in communities. The instrument, composed of five dimensions - aesthetic, artistic, participatory, axiological and territorial anchorage -, responds to a concept of cultural mediations manifested in the construction, reproduction and symbolic exchange produced between cultural factors, artistic devices, territory and the participating public of a community sociocultural project. A mixed approach was used in the research, where the results of several focus groups, expert rounds and statistical tests that demonstrate the validity and reliability of the instrument were triangulated. The items proposed for each dimension resulted from the analysis of literature, different focus groups with specialists in the subject and the validation by experts through the Delphi method. The internal consistency index showed a coefficient of .845, while in the exploratory factor analysis, the dimensions created were confirmed through the communalities that emerged. The exploratory factor analysis showed the correlation between all these dimensions. In the subscales the Cronbach's Alpha were satisfactory, as well as the correlation between items.
\end{abstract}

Keywords: cultural mediations, scale, sociocultural projects, art.

\section{Introducción}

a implementación de los proyectos socioculturales comunitarios permite el progreso y el desarrollo de la calidad de vida de sus miembros, basado en fórmulas eficaces direccionadas a la transformación de su realidad social. Los proyectos socioculturales comunitarios apremian la transformación de cada contexto con el objetivo de promover la existencia y desarrollo de un cambio progresivo desde el punto de vista cualitativo y cuantitativo (Baca-Tavira; Herrera-Tapia, 2016; Rosales-González, 2012). Las manifestaciones artísticas pueden convertirse en protagonistas del 
quehacer sociocultural-comunitario en diferentes espacios, a fin de lograr e incentivar la presencia de mayores niveles de participación, unificación, sentido de pertenencia e identidad, generando así un impacto social en la comunidad (Bang; Wajnerman, 2010).

Concebir indicadores de evaluación en las actividades artísticas y culturales es un desafío para los investigadores del área. Cuando se analizó la literatura nacional e internacional en búsqueda de un cuestionario validado por estudios científicos, se observó que la mayoría estuvo enfocada desde la participación, calidad de los servicios, las estrategias de promoción o de gestión (UNESCO, 2014a; 2014b). La escala que se valida en esta investigación parte de una mirada holística a las diferentes experiencias que vive un participante en algún evento cultural. Específicamente, surgió para analizar las mediaciones culturales o artísticas que se producen en los proyectos socioculturales comunitarios donde el arte participativo es el motor impulsor de estos.

Sobre mediaciones culturales, el debate teórico oscila principalmente en áreas de estudios como la comunicación, los estudios culturales, la jurisprudencia y existe una formulación conceptual alrededor de una profesión relacionada especialmente al área de las artes - el mediador cultural. El concepto de mediación cultural surge de las ideas propuestas por Martín-Barbero (1991), Orozco (1997) y Caune (2017). Sus principales aportes se encuentran en el análisis de la relación entre comunicación y cultura, el acto de mediación que se produce en cada proceso de interacción humana.

Las diferentes mediaciones culturales producidas en un proyecto sociocultural comunitario se pueden comprender a través de una mirada interdisciplinaria al fenómeno y desde diversas dimensiones. Los ámbitos de acción de las mediaciones culturales son concebidos principalmente en proyectos de educación artística y cultural, creación artística, conocimiento de obras de arte, integración cultural, integración socioeconómica y humanitaria, expresión de la identidad, desarrollo de nuevas prácticas y desarrollo local (Jacob; Bélanger, 2014). Desde la literatura se reconocen 
principalmente dos esferas de trabajo: por una parte, las perspectivas vinculadas a la "democratización de la cultura" en el sentido ordinario del término (accesibilidad, educación y conocimiento de las artes y la cultura), y por otro lado, las perspectivas relacionadas con la "democracia cultural", entendida como la valoración de la diversidad cultural y la expresión bajo todos sus formas, que también pueden expandir e integrar el pensamiento crítico, nuevo movimientos sociales, nuevas prácticas o prácticas alternativas (Scieur; Vanneste, 2015).

La mediación cultural no se puede reducir únicamente a una estrategia comunicacional para la satisfacción de la demanda cultural. Su concepción y análisis debe propiciar la participación de todos los actores sociales. Desde la opinión de los autores, nos encontramos con una visión de la cultura transformadora de realidades, no solo a nivel de comunidades sino personal también. La mediación cultural actúa como mecanismo de reconfiguración de relaciones entre artistas, públicos y aparatos institucionales. En ocasiones, el término mediaciones culturales es definido a partir de ciertas actividades que realiza un animador sociocultural: visitas guiadas, talleres, programación musical, de teatro, cine, comunitaria, entre otras (Rasse, 2000). Sin embargo, nos atañe la mediación cultural como una técnica de relación entre públicos (Chaumier; Mairesse, 2013).

La mediación cultural debe comprenderse en su sentido más amplio teniendo como base un concepto de cultura que se mueve desde su acepción antropológica hasta su forma más reducida como las manifestaciones del arte (Caune, 2017). Para ello, los actores sociales deben apropiarse de las viejas y nuevas formas del lenguaje artístico y de las técnicas de comunicación. Es un término que está ligado a la construcción de la colectividad luego de "el fin de las ideologías y la acción colectiva parece obsoleta" (Caune, 2017, p. 22). Partiendo de este contexto, la mediación cultural cumple tres funciones sociales emergentes: luchar contra el debilitamiento del vínculo social, reestructurar el sentimiento de pertenencia a la colectividad y finalmente, favorecer el nacimiento de nuevas formas (Caune, 2017). La mediación cultural debe centrar su análisis y desarrollo en tres aspectos importantes: 
el primero, enfatizar la relación entre los actores sociales; segundo, analizar el enunciado; y, como tercer elemento, preferir la recepción antes que la difusión (Lamizet, 2000; Chaumier; Mairesse, 2013).

Según Caune (2010), hay dos modos de acción para la mediación cultural: la mediación artística y la mediación estética. La mediación artística está relacionada con la transmisión de conocimientos al público: "incluye las acciones en torno al trabajo artístico, que son sobre el orden de la sensibilización, la presentación o la pedagogía" (Caune, 2010, p. 134). Esta mediación se dirige a públicos reales o potenciales. La mediación estética es de otro orden, el de los sentimientos experimentados durante el encuentro con la obra de arte, es "una relación establecida a través de un soporte sensible (una apariencia) entre una enunciación singular (una subjetividad) y un destinatario que está dirigido a lograr una experiencia estética" (Caune, 2010, p. 135).

Sin embargo, Chaumier y Mairesse (2013) no distinguen entre la mediación artística y la estética, sino la mediación estética de la cultural. Según ellos, la mediación estética es el mensaje "transmitido" a través de la creación artística; y la mediación cultural está en el nivel de "efectos que generan significado para el público mediante la posible reinversión de obras en su vida diaria" (Chaumier; Mairesse, 2013, p. 34). Según los autores, la convergencia de estas mediaciones puede provocar confusión, puesto que casi siempre suelen ser actores separados. Para ellos, la mediación cultural desaparece cuando estamos frente a la mediación estética en su forma restringida, es decir, la idea de un creador único de la obra de arte que comunica por si sola. Pensar en este registro las mediaciones es restringir su interpretación a la aproximación relacional entre la obra de arte y el público individual.

En este estudio se elaboró una escala que permite analizar las diferentes mediaciones culturales manifiestas por los participantes en un proyecto sociocultural comunitario en el que el arte es el leitmotif de desarrollo. La escala se construyó con ítems genéricos que permitieron "evadir" las particularidades de ciertas manifestaciones artísticas. Su aplicación permitirá 
identificar y valorar cuál de las dimensiones propuestas se desarrolla en el marco de un proyecto sociocultural comunitario.

Entre los participantes del proyecto y su entorno se generan una serie de lazos de cooperación que permiten no solamente su desarrollo, sino también la transformación del barrio (Ardenne, 2011). Estos lazos pueden ser entendidos como la solidaridad, el empoderamiento y la participación, no solo en las actividades del proyecto, sino en aquellas que lo relacionan también con el barrio (Bang, 2013). El problema radica en cómo estos lazos se solidifican con el tiempo de forma tal que, si los objetivos del proyecto se modifican, no se pierdan las capacidades, confianza, visión y protagonismo como grupo social para impulsar cambios positivos en las situaciones que viven.

Ante esta problemática, la dimensión "comunicación" juega un rol fundamental y se posiciona como un eje transversal para el objetivo que se quiere lograr (Jouët, 1993). La ventaja de esta visión es que los objetivos no se limitan al éxito de una intervención concreta, sino a una toma de conciencia y de autonomía por parte de los participantes del proyecto y de las personas que lo rodean. Desde este enfoque, las mediaciones culturales se ocupan de la trasmisión e intercambio activo de mensajes entre los participantes del proyecto permitiendo la influencia y transformación de sus criterios, percepciones y valoraciones acerca de sus realidades y cosmovisiones.

Las mediaciones culturales adoptan diferentes formas según el área de análisis. Cada una intenta adecuar un concepto "volátil" - en el sentido de acomodarlo fácilmente a situaciones teórico-prácticas - y convertirlo en una definición multinivel que se comprende desde lo micro hasta lo macro. De esta relación dialéctica entre teoría y práctica se construye el concepto fundamental de la investigación. El concepto defendido se sustenta justamente en aquellas mediaciones culturales que surgen en la construcción, reproducción e intercambio simbólico producido entre los factores culturales, los dispositivos y el público participante de un proyecto sociocultural comunitario. Las mediaciones culturales se sitúan en el centro 
del acto comunicativo diversificando, intencionalmente o no, la producción de significados en torno al arte, el proyecto sociocultural y el barrio o el territorio inmediato (Caune, 2017).

Cuando se sistematizan las características de los proyectos socioculturales comunitarios con el concepto de mediaciones culturales que defendemos, nos percatamos de que estas pueden mostrarse en el barrio a través de las siguientes dimensiones: experiencia estética (Marty et al., 2003; Myszkowski; Zenasni, 2016; Raychaudhuri, 1972), artística (Colignon, 2015; Loser, 2010; Saurier, 2015), de participación (Amado, 2010; Hernández-Belver; MartínPrada, 1998; Bang, 2013), dimensión axiológica (Caune, 2017; Colpé, 2018) y anclaje territorial (Baca-Tavira; Herrera-Tapia, 2016; Langeard; Liot; Rui, 2015; Eloy, 2015). Comprender el concepto de mediaciones culturales a través de estas dimensiones conlleva conocer desde su construcción teórica hasta las formas de aparición y de manifestación en el seno del proyecto. Lo que, en un principio, nace en la intención comunicativa del grupo gestor del proyecto sociocultural, con el tiempo puede convertirse en mediaciones culturales naturales y espontáneas en la vida de los participantes; interviniendo en su acto de cotidianidad para la construcción y reproducción de símbolos y significados.

La multifuncionalidad de las prácticas culturales es un componente básico de la dinámica de las comunidades. El desarrollo alcanzado por la comunidad, la riqueza de la cultura popular y las influencias mutuas, con su base económica, generan formas de pensar y actuar particulares - una forma de pensar y actuar colectivamente en la que importa mucho el grupo, pero en la que una o más personas crean diversas mediaciones culturales para que todos los miembros puedan ser parte de un proyecto de vida en conjunto. Una forma de pensar y actuar auténticamente comunitaria, donde personas se unen, participan y cooperan solidariamente a partir de lo poco que poseen. 


\section{Metodología}

La investigación se realizó con enfoque mixto. La propuesta final de la escala se fundamenta en la triangulación de los resultados obtenidos en varios focus groups y rondas de expertos, con pruebas estadísticas que demuestran la validez y confiabilidad del instrumento. La triangulación de resultados es un método que posibilita la sistematización de datos a través de disímiles técnicas en variados contextos, incluso con minorías vulnerables (Mejía-Arauz, 2003; Prickett; Angel, 2012). Para la construcción y validación de la escala se analizaron varios estudios (Chen; Starosta, 2000; EspinosaDíaz; Lloréns-Báez, 2015; Ramírez; Ruiz; Torrente, 2014; UNESCO, 2014a, 2014b) resultando las siguientes etapas: (1) elaboración de los ítems por categorías y algunas preguntas de control; (2) validación de la escala a través del método Delphi; (3) aplicación del cuestionario a la muestra seleccionada; (4) análisis de los resultados; finalmente, (5) discusiones y presentación final de la escala. Se utilizó el programa estadístico SPSS 24 y su extensión AMOS 24.

\section{Elaboración de los ítems por categorías}

Luego de analizar los referentes teóricos conceptuales sobre el concepto de mediaciones culturales se procedió a recopilar la información necesaria desde la visión y experiencia de varias personas. Dos focus groups se planificaron con líderes de proyectos, algunos artistas del barrio y personas pertenecientes a las áreas de comunicación y trabajo comunitario. Sin embargo, por proposición de los participantes, surgió otro encuentro con más especialistas de la temática que fueron recomendados y propuestos por ellos. Un total de 23 colaboradores conformaron estas reuniones: siete especialistas en el área de comunicación y cuatro en el área del trabajo comunitario, 12 artistas y líderes de proyectos; además de otra persona que participó de moderador de los encuentros.

Inicialmente, el moderador explicó a los participantes el objetivo de la investigación y lo que se quería lograr con la escala. Los primeros debates 
se centraron en la viabilidad de las categorías de análisis propuestas y su interrelación. Posteriormente se debatió la construcción de los ítems que podían conformar cada dimensión anteriormente analizada. La diversidad de especialistas presentes provocó que las discusiones no solo se centraran en la construcción de la escala, sino también, en comprender las mediaciones culturales desde su relación intrínseca con el artista, la obra y los públicos. Sin embargo, concordaron en la pertinencia de analizar las mediaciones culturales en el acto comunicativo cotidiano, y cómo los proyectos socioculturales comunitarios son creadores de nuevas formas de mediación entre las personas y su entorno inmediato.

Luego de tres jornadas de trabajo, aproximadamente de una hora y media de discusiones, se procedió a analizar la información recopilada. Se organizaron y analizaron las grabaciones y las notas tomadas durante las sesiones de trabajo. El análisis de contenido permitió crear 67 ítems alrededor de las categorías de análisis, siendo la mayor cantidad para medir la experiencia estética y artística de los participantes como principales formas de mediación en el seno del proyecto.

\section{Validación de la escala a través del método Delphi}

El método Delphi es una metodología estructurada para recolectar sistemáticamente juicios de expertos sobre un problema, procesar la información y, a través de recursos estadísticos, construir un acuerdo general de grupo. Permite la transformación durante la investigación de las apreciaciones individuales de los expertos en un juicio colectivo superior. El método, según Astigarraga (2005), se realiza en cuatro fases: detección del problema, selección de expertos, aplicación de rondas y búsqueda de consenso. Nuestro problema inicial es la validación de la escala de mediaciones culturales, en contextos donde se desarrollan proyectos socioculturales comunitarios, que permita su identificación y medición en las prácticas comunitarias. La selección de expertos se desarrolló siguiendo el procedimiento propuesto por (Oñate-Martínez; 
Ramos-Morales; Díaz-Armesto, 1988). Inicialmente se construyó una lista de expertos que dominaban el tema, se analizaron las posibilidades de que los participantes no se conocieran, aunque en la práctica esto es algo que no se pudo verificar.

Como el término de experto es debatido constantemente en la literatura, para la selección de los participantes se definieron las siguientes características de inclusión: coeficiente de competencia (Kcomp) ${ }^{1}$ esperado y tener más de 10 años de experiencia de investigación en la temática o áreas afines, siendo el primer criterio fundamental para la selección. Como se evidencia en la Tabla 1, de los 17 expertos propuestos inicialmente, solo 11 cumplieron los requisitos de selección. Dos expertos, aunque el Kcomp se encontraba entre los valores recomendados por los autores, no cumplieron con los años de experiencia especificados en los criterios de selección.

El proceso se estableció a partir de tres rondas de análisis. La primera ronda, compuesta por preguntas abiertas y cerradas, estuvo encaminada a validar las categorías de análisis y los ítems que conformaban cada una. La segunda, solo de preguntas cerradas, se utilizó para depurar los ítems por categorías con la intención de reducirlos. Finalmente, la tercera ronda, sirvió para consensuar las cinco categorías finales y los diferentes ítems que conformaban la escala, siendo estos 34, más tres preguntas de control general.

${ }^{1}$ El coeficiente competencia (Oñate-Martínez et al., 1988) se compone de un coeficiente de conocimiento $(\mathrm{kc})$ y otro de argumentación (Ka). El cálculo se realiza a través de la siguiente ecuación: kcomp $=0,5 *(k c+K a)$.

Donde se establecen los siguientes rangos:

Si $0.8<$ Kcomp $<1.0$ coeficiente de competencia alto.

Si $0.5<$ Kcomp $<0.8$ coeficiente de competencia medio

Si Kcomp $<0.5$ coeficiente de competencia bajo

Coeficiente de conocimiento $\left(K_{c}\right)$ se calcula a través de una escala del $0-10$, donde el cero representa el nivel más bajo de conocimiento y 10 el valor más alto. El valor resultante se multiplica por 0.1 .

Coeficiente de argumentación (ka) se obtiene a través una tabla donde el experto señala su nivel de argumentación en los rangos de alto, medio, bajo y se calcula sobre la base de la suma del grado de influencia de cada ítem. 
Tabla 1 - Análisis para la selección de expertos

\begin{tabular}{|c|c|c|c|c|c|}
\hline \multirow{2}{*}{ Experto } & \multicolumn{2}{|c|}{ Componentes } & $\begin{array}{c}\text { Kcomp= 0,5 } \\
\text { (Kc + Ka) }\end{array}$ & $\begin{array}{c}\text { Años de } \\
\text { investigación }\end{array}$ & $\begin{array}{c}\text { Decisión } \\
\text { SI/NO }\end{array}$ \\
\cline { 2 - 6 } & Kc & Ka & Kcomp & & \\
\hline E1 & 0,80 & 0,90 & 0,85 & 17 & SI \\
\hline E2 & 1,00 & 1,00 & 1,00 & 19 & SI \\
\hline E3 & 0,90 & 0,95 & 0,93 & 23 & SI \\
\hline E4 & 0,70 & 0,80 & 0,75 & 16 & $\mathrm{SI}$ \\
\hline E5 & 0,40 & 0,50 & 0,45 & 7 & $\mathrm{NO}$ \\
\hline E6 & 0,80 & 0,75 & 0,78 & 8 & $\mathrm{NO}$ \\
\hline E7 & 0,90 & 0,80 & 0,85 & 15 & $\mathrm{SI}$ \\
\hline E8 & 0,90 & 0,90 & 0,90 & 12 & $\mathrm{SI}$ \\
\hline E9 & 0,70 & 0,60 & 0,65 & 12 & $\mathrm{NO}$ \\
\hline E10 & 0,90 & 0,90 & 0,90 & 21 & $\mathrm{SI}$ \\
\hline E11 & 0,70 & 0,95 & 0,83 & 16 & $\mathrm{SI}$ \\
\hline E12 & 0,60 & 0,50 & 0,55 & 11 & $\mathrm{NO}$ \\
\hline E13 & 0,50 & 0,50 & 0,50 & 7 & $\mathrm{NO}$ \\
\hline E14 & 0,70 & 0,80 & 0,75 & 11 & $\mathrm{SI}$ \\
\hline E15 & 0,70 & 1,00 & 0,85 & 14 & $\mathrm{SI}$ \\
\hline E16 & 0,70 & 1,00 & 0,85 & 12 & $\mathrm{SI}$ \\
\hline E17 & 0,80 & 0,65 & 0,73 & $\mathrm{NO}$ \\
\hline
\end{tabular}

Fuente: Elaboración propia.

\section{Contextualización y participantes del estudio}

Esta investigación se desarrolló en La Habana, Cuba. En las últimas décadas se evidenció el auge de proyectos socioculturales comunitarios a lo largo de la ciudad, sobre todo en los municipios periféricos. Diferentes artistas del territorio se organizaron con los miembros de su barrio y emprendieron iniciativas comunitarias para transformar la realidad cultural de su entorno. 
Para la selección de los proyectos se consensuaron diferentes criterios: (1) la manifestación artística principal - los proyectos utilizados en la investigación giraron en torno a: la música, la danza, el teatro, la pintura, la literatura; (2) tiempo de vida - se seleccionaron proyectos con más de tres años de ejecución; (3) público con el que trabaja - presencia y participación en el proyecto de personas de diferentes edades (por la complejidad del instrumento y quizás su difícil comprensión, no se aplicó a niños y niñas); (4) situación geográfica - se escogieron proyectos de las cuatro regiones principales de La Habana; y, por último, (5) los proyectos surgieron de un proceso endógeno de los actores territoriales. Estas características de inclusión permitieron aplicar el instrumento en una diversidad de contextos socioculturales y formas de organización, gestión e implementación de acciones comunitarias.

\section{Aplicación del instrumento}

El cuestionario se concibió con cinco categorías iniciales de análisis y las tres preguntas de control (ver tabla 8, en el Apéndice). Los ítems se presentaron en la escala inicial de forma desorganizada para evitar una tendencia en las respuestas y que el encuestado reflexionara ante las diferencias de los planteamientos. Se utilizó un escalamiento tipo Likert con siete opciones de respuesta (1- totalmente en desacuerdo, 2- en desacuerdo, 3- probablemente en desacuerdo, 4- ni de acuerdo ni en desacuerdo, 5probablemente de acuerdo, 6- de acuerdo, y 7-totalmente de acuerdo). Para esta propuesta se tomaron en cuenta los estudios de Smith-Castro (2002) quien aumentó las opciones de respuestas de 4 a 6 en la validación de un instrumento en el contexto costarricense. Por su parte, Hammer, Bennett e Wiseman (2003) utilizaron entre 1 y 7 opciones de respuestas para la construcción y validación de una escala sobre interculturalidad. Estos autores reconocen que se obtiene mayor variabilidad en los resultados con un mayor número de opciones de respuestas. 
La escala de mediaciones culturales se administró a 294 participantes de diferentes zonas del territorio habanero. Los criterios de inclusión en la muestra fueron: ser integrantes activos del proyecto sociocultural, no limitarse a espectadores frecuentes; más de seis meses de participación en las actividades; $y$, finalmente, formar parte del territorio de acción del proyecto. Para este último requerimiento se les explicó a los encuestados los posibles límites geográficos que comprendían este territorio de acción.

Para aplicar los cuestionarios, se analizó la programación de los proyectos y se delimitaron los días de mayor afluencia. Posteriormente, nos comunicamos con los líderes o los responsables del proyecto con el objetivo de verificar la actividad e informar nuestra presencia aplicando el cuestionario. Cuatro semanas se utilizaron en la aplicación del instrumento; el equipo, conformado por tres personas, conocía las normas de interacción con los encuestados. Igualmente se cumplió los criterios de estratificación propuestos inicialmente en el muestreo.

El muestreo aleatorio estratificado se realizó siguiendo el procedimiento de rutas aleatorias. Para la definición de los estratos se tuvo en cuenta la manifestación artística principal del proyecto, obteniéndose cinco grupos de la muestra total: música $(23,6 \%)$, danza $(18,1 \%)$, literatura $(16,9 \%)$, artes plásticas $(24,7 \%)$ y artes escénicas $(13,7 \%)$. Del total de la muestra, se eliminaron 26 participantes (8,84\%) por no cumplir algunos los criterios de selección, u otros Ilenaron incorrectamente la encuesta. Luego de desechar las encuestas incorrectas o nulas, pudimos determinar algunos estadísticos descriptivos. En el estudio participaron 114 (42,5\%) personas del sexo masculino y 154 (57,5\%) personas del sexo femenino. El 55,6 \% manifestó ser partícipe del proyecto por más de cinco años, seguido por el rango entre un y dos años con el 24,6 \%, mientras que el resto oscila en un año o entre tres y cinco años. 


\section{Análisis de resultados}

\section{Análisis factorial exploratório (AFE)}

Del total de cuestionarios aplicados, 268 fueron analizados para la validación de la escala. Inicialmente, la escala tuvo 34 ítems, los cuales habían sido validados por el juicio de expertos. En el proceso de depuración de la escala, el análisis factorial exploratorio, utilizando la prueba de adecuación de muestreo $(\mathrm{KMO})$ y de esfericidad de Bartlett con rotación Varimax, mostró que siete ítems no superaban el valor de 0.5 y, por ende, no se agrupaban en ningún factor, siendo estos eliminados. De las tres preguntas de control, solo una se consideró para el cuestionario final, puesto que las restantes no superaban a 0.5 el índice de correlación y carga factorial. El índice de adecuación muestral $(\mathrm{KMO})$ resultó adecuado $(0,838)$, así como la prueba de esfericidad de Bartlett $\chi^{2}(300)=2849.36$ y $\mathrm{p}<0.000$.

El análisis factorial exploratorio se empleó como método de reducción de datos para explicar las correlaciones entre las variables observadas y la construcción de nuevos factores latentes. Aunque se obtuvieron las comunalidades inicialmente propuestas, algunos ítems fueron eliminados de la escala por no mostrar los índices de relación aceptados con algún factor en específico. Todas las subescalas perdieron ítems: factor 1 (experiencia estética) perdió un ítem y quedó compuesto por los siguientes 1, 12, 7, 13, 18, 22 (total 6); factor 2 (participación) se eliminó un ítem, lo componen los ítems 2, 8, 14, 19, 23 (total 5); factor 3 (dimensión axiológica) se excluyeron dos ítems quedando los ítems 3, 9, 15, 24 (total 4); factor 4 (experiencia artística) se eliminó un ítem y quedaron los siguientes 4, 10, 16, 20, 25; el factor 5 (anclaje territorial) lo conforman cuatro ítems 5 , $11,17,21$ luego de haber eliminado dos ítems que no superaban el valor de 0.5. Finalmente, la pregunta de control fue un solo factor y quedó como el ítem seis. Los 5 factores agrupan el 60.514 de la varianza total, mostrando que el agrupamiento factorial es favorable para la escala. La Tabla 2 muestra el análisis grupal final organizado con los ítems finales por categorías y numerados en el orden de presentación que tendrán en la versión final del cuestionario. 
Tabla 2 - Análisis factorial exploratorio (AFE)

\begin{tabular}{|c|c|c|c|c|c|c|c|}
\hline \multicolumn{8}{|c|}{ Matriz de componente rotado ${ }^{a}$} \\
\hline \multicolumn{2}{|c|}{ Planteamiento } & \multirow{2}{*}{$\frac{1}{0,877}$} & \multirow{2}{*}{$\frac{2}{0,059}$} & \multirow{2}{*}{$\frac{3}{-0,085}$} & \multirow{2}{*}{$\frac{4}{-0,040}$} & \multirow{2}{*}{$\frac{5}{0,040}$} & \multirow{2}{*}{$\frac{6}{0,012}$} \\
\hline I1 & $\begin{array}{l}\text { Me siento bien cuando asisto a las } \\
\text { actividades culturales }\end{array}$ & & & & & & \\
\hline 112 & $\begin{array}{l}\text { Considero que mi capacidad de } \\
\text { creación e imaginación aumentó con } \\
\text { las actividades culturales }\end{array}$ & 0,822 & 0,060 & 0,004 & 0,013 & 0,059 & $-0,007$ \\
\hline 17 & $\begin{array}{l}\text { Los acontecimientos y actividades } \\
\text { artísticas enriquecen mi experiencia } \\
\text { estética }\end{array}$ & 0,821 & 0,198 & 0,038 & $-0,007$ & 0,080 & 0,024 \\
\hline 113 & $\begin{array}{l}\text { Me satisface crear algo que otros } \\
\text { podrían disfrutar }\end{array}$ & 0,794 & 0,243 & 0,011 & 0,007 & 0,091 & $-0,091$ \\
\hline 118 & $\begin{array}{l}\text { Me mantengo aprendiendo nuevas } \\
\text { formas de vivir y pensar }\end{array}$ & 0,649 & $-0,074$ & $-0,008$ & $-0,010$ & 0,398 & 0,262 \\
\hline 122 & Siento que el arte es parte de mí & 0,642 & 0,120 & 0,001 & $-0,030$ & 0,444 & 0,270 \\
\hline 12 & $\begin{array}{l}\text { Participo proactivamente en las } \\
\text { actividades culturales }\end{array}$ & 0,068 & 0,860 & 0,100 & 0,063 & 0,050 & $-0,006$ \\
\hline 18 & $\begin{array}{l}\text { Considero que en la creación de las } \\
\text { actividades culturales participa todo } \\
\text { el colectivo }\end{array}$ & 0,011 & 0,838 & 0,088 & $-0,042$ & $-0,056$ & 0,111 \\
\hline 114 & $\begin{array}{l}\text { Pienso que mi creatividad aumenta } \\
\text { con la participación en las actividades }\end{array}$ & 0,211 & 0,779 & 0,070 & 0,002 & 0,034 & 0,014 \\
\hline I19 & $\begin{array}{l}\text { He aprendido que existen muchas } \\
\text { formas de participar en las actividades } \\
\text { culturales }\end{array}$ & 0,108 & 0,753 & $-0,031$ & 0,053 & 0,254 & $-0,001$ \\
\hline 123 & $\begin{array}{l}\text { Cuando participo trato de dar lo mejor } \\
\text { de mí }\end{array}$ & 0,229 & 0,731 & $-0,066$ & 0,012 & 0,280 & $-0,066$ \\
\hline 13 & $\begin{array}{l}\text { Las actividades culturales me permiten } \\
\text { conocer nuevas personas }\end{array}$ & 0,024 & $-0,030$ & 0,837 & 0,064 & $-0,044$ & $-0,098$ \\
\hline 19 & $\begin{array}{l}\text { Las artes contribuyen a la educación y } \\
\text { el desarrollo de todas las personas }\end{array}$ & $-0,021$ & 0,111 & 0,818 & 0,069 & 0,094 & 0,168 \\
\hline I15 & $\begin{array}{l}\text { He aprendido a tratar personas de } \\
\text { culturas diferentes }\end{array}$ & $-0,026$ & 0,067 & 0,817 & 0,035 & $-0,011$ & $-0,010$ \\
\hline 124 & $\begin{array}{l}\text { Siento que puedo comprender mejor } \\
\text { las perspectivas de otros }\end{array}$ & 0,025 & 0,032 & 0,691 & 0,321 & 0,073 & 0,050 \\
\hline 14 & $\begin{array}{l}\text { Considero que tenemos libertad } \\
\text { de actuación y de expresión en las } \\
\text { actividades culturales }\end{array}$ & $-0,034$ & 0,005 & 0,364 & 0,718 & 0,187 & $-0,108$ \\
\hline I10 & $\begin{array}{l}\text { Logro expresarme a través de las } \\
\text { manifestaciones artísticas }\end{array}$ & $-0,035$ & $-0,001$ & 0,144 & 0,707 & 0,046 & $-0,131$ \\
\hline
\end{tabular}

Método de extracción: análisis de componentes principales. 
(cont.)

\begin{tabular}{|c|l|c|c|c|c|c|c|}
\hline $\mathbf{I 1 6}$ & $\begin{array}{l}\text { Intento descubrir nuevos significados } \\
\text { en, y a través de la obra artística }\end{array}$ & $-0,058$ & $-0,051$ & 0,297 & 0,683 & 0,204 & $-0,075$ \\
\hline $\mathbf{I 2 0}$ & $\begin{array}{l}\text { Siento que mis capacidades y } \\
\text { habilidades artísticas se han fortalecido }\end{array}$ & $-0,009$ & 0,056 & $-0,143$ & 0,644 & $-0,209$ & 0,077 \\
\hline $\mathbf{I 2 5}$ & $\begin{array}{l}\text { Me parece que mi potencial de } \\
\text { creación artística ha aumentado }\end{array}$ & 0,166 & 0,127 & $-0,023$ & 0,514 & $-0,345$ & 0,284 \\
\hline $\mathbf{I 5}$ & $\begin{array}{l}\text { Las actividades culturales influyen } \\
\text { positivamente en la zona donde vivo }\end{array}$ & 0,318 & 0,081 & 0,043 & 0,002 & 0,612 & 0,149 \\
\hline $\mathbf{I 1 1}$ & $\begin{array}{l}\text { Participar en las actividades culturales } \\
\text { aumentó mi sentimiento de } \\
\text { pertenencia hacia mi barrio }\end{array}$ & 0,513 & 0,238 & 0,077 & $-0,004$ & 0,581 & $-0,017$ \\
\hline $\mathbf{I 1 7}$ & $\begin{array}{l}\text { Para mi es importante que mi barrio } \\
\text { sea considerado un centro cultural }\end{array}$ & 0,362 & 0,331 & 0,025 & 0,024 & 0,518 & 0,214 \\
\hline $\mathbf{I 2 1}$ & $\begin{array}{l}\text { Siento que en mi barrio la } \\
\text { participación y los lazos de } \\
\text { cooperación entre personas se han } \\
\text { fortalecido }\end{array}$ & 0,017 & 0,366 & 0,040 & 0,065 & 0,509 & $-0,239$ \\
\hline $\mathbf{I 6}$ & $\begin{array}{l}\text { Las actividades culturales comunitarias } \\
\text { posibilitan nuevas dinámicas de } \\
\text { cohesión, participación y significados } \\
\text { que reconfiguran su vida diaria. }\end{array}$ & 0,073 & 0,017 & 0,070 & $-0,083$ & 0,086 & 0,853 \\
\hline
\end{tabular}

Método de rotación: Varimax con normalización Kaiser.

Fuente: Elaboración propia.

\section{Análisis factorial confirmatorio (AFC)}

El análisis factorial confirmatorio se realizó con la extensión AMOS del programa estadístico SPSS. Su principal objetivo fue analizar las cargas correlacionales establecidas entre los factores arrojados. Como se evidencia en la Figura 1 todas las comunalidades establecieron una correlación por encima de 0,5 ; aunque algunas más significativas que otras. Los factores más correlacionados fueron: (F1) experiencia estética y (F5) anclaje territorial $(\rho=0,74)$; (F1) experiencia estética y (F4) dimensión artística $(\rho=0,73)$; (F2) participación y (F4) dimensión artística $(\rho=0,68)$ y, finalmente, (F3) dimensión axiológica y (F5) anclaje territorial $(\rho=0,66)$. Las pruebas estadísticas de reducción de dimensiones muestran la relación entre las categorías que conforman el cuestionario. 
Figura 1 - Análisis factorial confirmatorio

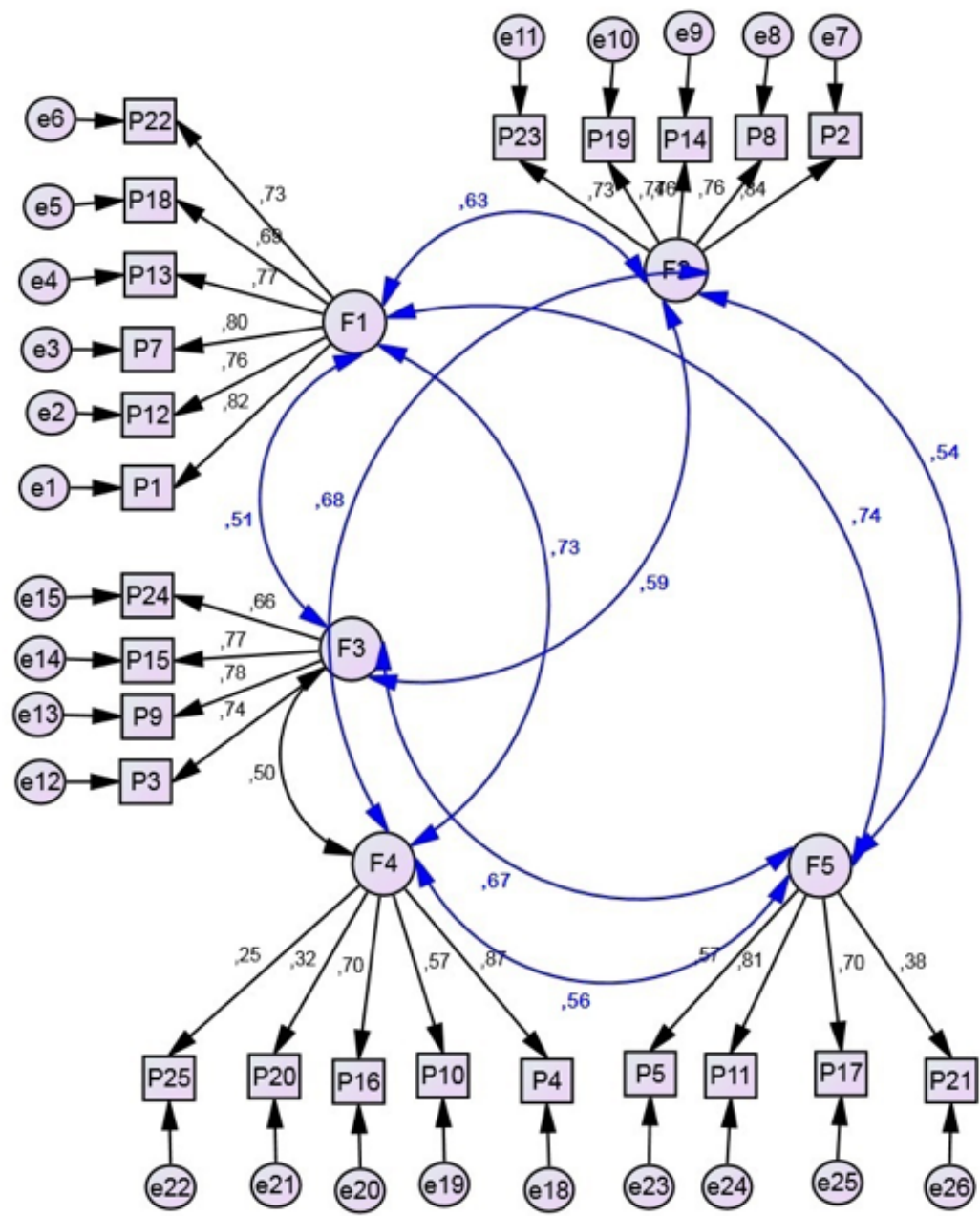

Leyenda: F1-experiencia estética; F2-participación; F3- dimensión axiológica; F4dimensión artística; F5-anclaje territorial.

Fuente: Elaboración propia. 


\section{Análisis de fiabilidad}

Los estudios sobre la consistencia interna del cuestionario muestran un coeficiente de alpha de Cronbach para la escala general de 0,845.

\section{Análisis entre ítems de un mismo factor}

A continuación, se explican las correlaciones entre los ítems de un mismo factor o dimensión. El objetivo principal es analizar si la correlación existente coincide con la esperada y si existe complementariedad entre ellos. Las tablas muestran una tendencia general en las repuestas y, en todos los factores, las correlaciones son significativas. En este análisis se excluye el I6 (pregunta de control) que no se ubicó en ningún factor; sin embargo, su nivel de significancia fue de los más elevados en el análisis factorial exploratorio.

\section{EXPERIENCIA ESTÉTICA}

Como se observa en la Tabla 3, todos los ítems están correlacionados entre sí con un nivel de significancia importante. La correlación más elevada se estableció entre el I1 y el I12 ( $\rho=0,749)$, lo cual presupone que cuando una persona participa de la actividad cultural considera que aumenta su nivel de creación e imaginación. Este resultado es relevante, pues muestra que esta realidad se ajusta con lo expresado por Myszkowski y Zenasni (2016) al explicar este suceso en sus estudios teóricos. El I7 y el I13 $(\rho=0,718)$ revelaron alto índice de relación y muestra cómo en el acto de creación pensado para el disfrute de otros enriquece su experiencia estética. El coeficiente del Alpha de Cronbach en esta dimensión fue de 0,892, siendo esta puntuación fiable para la escala. 
Tabla 3 - Correlación de Pearson de la dimensión experiencia estética

\begin{tabular}{|c|c|c|c|c|c|c|c|}
\hline \multicolumn{8}{|c|}{ Experiencia estética } \\
\hline \multicolumn{8}{|c|}{ Correlaciones } \\
\hline & & I1 & 17 & $\mathbf{I 1 2}$ & I13 & I18 & 122 \\
\hline \multirow[t]{3}{*}{ I1 } & Correlación de Pearson & 1 & $658^{* *}$ &, $749 * *$ & $629 * *$ &, $552 * *$ &, $555^{* *}$ \\
\hline & Sig. (bilateral) & & 0,000 & 0,000 & 0,000 & 0,000 & 0,000 \\
\hline & $\mathrm{N}$ & 268 & 268 & 268 & 268 & 268 & 268 \\
\hline \multirow[t]{3}{*}{17} & Correlación de Pearson &, $658^{* *}$ & 1 &, $572 * *$ &, $718^{* *}$ &, $535^{* *}$ &, $563^{* *}$ \\
\hline & Sig. (bilateral) & 0,000 & & 0,000 & 0,000 & 0,000 & 0,000 \\
\hline & N & 268 & 268 & 268 & 268 & 268 & 268 \\
\hline \multirow[t]{3}{*}{112} & Correlación de Pearson &, $749 * *$ &, $572^{* *}$ & 1 &, $559 * *$ & $493^{* *}$ & $488^{* *}$ \\
\hline & Sig. (bilateral) & 0,000 & 0,000 & & 0,000 & 0,000 & 0,000 \\
\hline & $\mathrm{N}$ & 268 & 268 & 268 & 268 & 268 & 268 \\
\hline \multirow[t]{3}{*}{ I13 } & Correlación de Pearson &, $629 * *$ &, $718^{* *}$ &, $559 * *$ & 1 & $455^{* *}$ &, $531 * *$ \\
\hline & Sig. (bilateral) & 0,000 & 0,000 & 0,000 & & 0,000 & 0,000 \\
\hline & $\mathrm{N}$ & 268 & 268 & 268 & 268 & 268 & 268 \\
\hline \multirow[t]{3}{*}{ I18 } & Correlación de Pearson &, $552^{* *}$ &, $535^{* *}$ &, $493 * *$ & $455^{* *}$ & 1 &, $630 * *$ \\
\hline & Sig. (bilateral) & 0,000 & 0,000 & 0,000 & 0,000 & & 0,000 \\
\hline & $\mathrm{N}$ & 268 & 268 & 268 & 268 & 268 & 268 \\
\hline \multirow[t]{3}{*}{122} & Correlación de Pearson &, $555^{* *}$ &, $563^{* *}$ &, $488^{* *}$ &, $531 * *$ &, $630^{* *}$ & 1 \\
\hline & Sig. (bilateral) & 0,000 & 0,000 & 0,000 & 0,000 & 0,000 & \\
\hline & $\mathrm{N}$ & 268 & 268 & 268 & 268 & 268 & 268 \\
\hline
\end{tabular}

** La correlación es significativa en el nivel 0,01 (bilateral).

Fuente: Elaboración propia.

\section{Participación}

La Tabla 4 evidencia que los ítems de esta categoría se encuentran correlacionados significativamente. Cuando se analizan las correlaciones entre algunos de ellos, salta un elemento interesante: precisamente, que la más alta correlación se establece entre el I19 y el I23 ( $\rho=0,702)$. Esta correlación se explica en algunas teorías (Hernández-Belver; Martín-Prada, 
1998) que fundamentan cómo las formas de participación en un proyecto sociocultural comunitario se diversifican y las personas ven en este hecho un elemento importante para dar lo mejor de sí en este acto, al sentirse identificados y satisfechos participando. La fiabilidad entre los ítems de esta dimensión es aceptable con el valor de 0,874.

Tabla 4 - Correlación de Pearson de la dimensión participación

\begin{tabular}{|c|c|c|c|c|c|c|}
\hline \multicolumn{7}{|c|}{ Participación } \\
\hline \multicolumn{7}{|c|}{ Correlaciones } \\
\hline & & 12 & 18 & I14 & I19 & 123 \\
\hline \multirow[t]{3}{*}{12} & Correlación de Pearson & 1 &, $677^{* *}$ &, $665^{* *}$ &, $591 * *$ &, $575^{* *}$ \\
\hline & Sig. (bilateral) & & 0,000 & 0,000 & 0,000 & 0,000 \\
\hline & $\mathrm{N}$ & 268 & 268 & 268 & 268 & 268 \\
\hline \multirow[t]{3}{*}{18} & Correlación de Pearson & $677^{* *}$ & 1 &, $629 * *$ &, $531 * *$ &, $490 * *$ \\
\hline & Sig. (bilateral) & 0,000 & & 0,000 & 0,000 & 0,000 \\
\hline & $\mathrm{N}$ & 268 & 268 & 268 & 268 & 268 \\
\hline \multirow[t]{3}{*}{114} & Correlación de Pearson &, $665^{* *}$ & $629 * *$ & 1 & $474^{* *}$ &, $503 * *$ \\
\hline & Sig. (bilateral) & 0,000 & 0,000 & & 0,000 & 0,000 \\
\hline & $\mathrm{N}$ & 268 & 268 & 268 & 268 & 268 \\
\hline \multirow[t]{3}{*}{ I19 } & Correlación de Pearson &, $591 * *$ &, $531^{* *}$ & $474^{* *}$ & 1 &, $702^{* *}$ \\
\hline & Sig. (bilateral) & 0,000 & 0,000 & 0,000 & & 0,000 \\
\hline & $\mathrm{N}$ & 268 & 268 & 268 & 268 & 268 \\
\hline \multirow[t]{3}{*}{123} & Correlación de Pearson &, $575^{* *}$ & $490^{* *}$ &, $503 * *$ &, $702 * *$ & 1 \\
\hline & Sig. (bilateral) & 0,000 & 0,000 & 0,000 & 0,000 & \\
\hline & $\mathrm{N}$ & 268 & 268 & 268 & 268 & 268 \\
\hline
\end{tabular}

** La correlación es significativa en el nivel 0,01 (bilateral).

Fuente: Elaboración propia.

\section{Dimensión AXIOLÓGICA}

Esta dimensión fue una de las más debatidas durante los focus groups, incluso entre los expertos; construir ítems que pudieran ser generales y que no se basaran en la especificidad de cada proyecto constituyó un reto. 
Como se aprecia en la Tabla 5, todos los ítems están correlacionados con un nivel de significancia considerable. En el análisis factorial exploratorio, se mostró un alto nivel de comunalidad entre los ítems al tener tres de los cuatro resultantes con valores por encima de 0.8 en las cargas factoriales. La correlación de Pearson más alta de esta categoría se establece entre el 19 y el I15 $(\rho=, 584)$, evidenciando que a través del arte se pueden establecer nuevas formas de desarrollo humano y comprensión de la realidad. El coeficiente del Alpha de Cronbach en esta dimensión fue de 0.820, siendo esta puntuación fiable para la escala.

Tabla 5 - Correlación de Pearson de la dimensión axiológica

\begin{tabular}{|c|c|c|c|c|c|}
\hline \multicolumn{6}{|c|}{ Dimensión axiológica } \\
\hline \multicolumn{6}{|c|}{ Correlaciones } \\
\hline & & 13 & 19 & 115 & 124 \\
\hline \multirow[t]{3}{*}{ I3 } & Correlación de Pearson & 1 &, $540 * *$ &, $584 * *$ &, $567^{* *}$ \\
\hline & Sig. (bilateral) & & 0,000 & 0,000 & 0,000 \\
\hline & $\mathrm{N}$ & 268 & 268 & 268 & 268 \\
\hline \multirow[t]{3}{*}{19} & Correlación de Pearson &, $540 * *$ & 1 &, $656^{* *}$ & $488^{* *}$ \\
\hline & Sig. (bilateral) & 0,000 & & 0,000 & 0,000 \\
\hline & $\mathrm{N}$ & 268 & 268 & 268 & 268 \\
\hline \multirow[t]{3}{*}{ I15 } & Correlación de Pearson &, $584^{* *}$ &, $656^{* *}$ & 1 & $408^{* *}$ \\
\hline & Sig. (bilateral) & 0,000 & 0,000 & & 0,000 \\
\hline & $\mathrm{N}$ & 268 & 268 & 268 & 268 \\
\hline \multirow[t]{3}{*}{124} & Correlación de Pearson &, $567^{* *}$ & $488^{* *}$ & $408^{* *}$ & 1 \\
\hline & Sig. (bilateral) & 0,000 & 0,000 & 0,000 & \\
\hline & $\mathrm{N}$ & 268 & 268 & 268 & 268 \\
\hline
\end{tabular}

** La correlación es significativa en el nivel 0,01 (bilateral).

Fuente: Elaboración propia. 


\section{Dimensión ARTíSTICA}

Como se puede apreciar en la Tabla 6, todos los ítems están correlacionados con un nivel de significancia importante. El I4 y el 116 tienen la correlación más significativa de la categoría $(\rho=, 614)$ y muestran la relación existente entre las formas de libertad de expresión y actuación con la creatividad de los participantes en el proyecto. Igualmente, la libertad de expresión y actuación (14) está relacionada con el reconocimiento de los participantes en lograr expresarse a través de las manifestaciones artísticas. El coeficiente del Alpha de Cronbach en esta dimensión fue de 0,695, siendo esta puntuación fiable para la escala.

Tabla 6 - Correlación de Pearson de la dimensión artística

\begin{tabular}{|c|c|c|c|c|c|c|}
\hline \multicolumn{7}{|c|}{ Experiencia artística } \\
\hline \multicolumn{7}{|c|}{ Correlaciones } \\
\hline & & P4 & P10 & P16 & P20 & P25 \\
\hline \multirow[t]{3}{*}{14} & Correlación de Pearson & 1 & $490 * *$ & $614^{* *}$ & $262^{* *}$ & $196^{* *}$ \\
\hline & Sig. (bilateral) & & 0,000 & 0,000 & 0,000 & 0,000 \\
\hline & $\mathrm{N}$ & 268 & 268 & 268 & 268 & 268 \\
\hline \multirow[t]{3}{*}{ I10 } & Correlación de Pearson & $490^{* *}$ & 1 & $383^{* *}$ & $273^{* *}$ & $264^{* *}$ \\
\hline & Sig. (bilateral) & 0,000 & & 0,000 & 0,000 & 0,000 \\
\hline & $\mathrm{N}$ & 268 & 268 & 268 & 268 & 268 \\
\hline \multirow[t]{3}{*}{ I16 } & Correlación de Pearson & $614^{* *}$ & $383^{* *}$ & 1 & $247^{* *}$ &, $137^{*}$ \\
\hline & Sig. (bilateral) & 0,000 & 0,000 & & 0,000 & 0,000 \\
\hline & $\mathrm{N}$ & 268 & 268 & 268 & 268 & 268 \\
\hline \multirow[t]{3}{*}{120} & Correlación de Pearson & $262^{* *}$ & $273^{* *}$ & $247^{* *}$ & 1 & $236 * *$ \\
\hline & Sig. (bilateral) & 0,000 & 0,000 & 0,000 & & 0,000 \\
\hline & $\mathrm{N}$ & 268 & 268 & 268 & 268 & 268 \\
\hline \multirow[t]{3}{*}{ I25 } & Correlación de Pearson & $196 * *$ & $264^{* *}$ &, $137^{*}$ & $236 * *$ & 1 \\
\hline & Sig. (bilateral) & 0,000 & 0,000 & 0,00 & 0,000 & \\
\hline & $\mathrm{N}$ & 268 & 268 & 268 & 268 & 268 \\
\hline
\end{tabular}

Fuente: Elaboración propia. 


\section{ANCLAJE TERRITORIAL}

La última subescala que compone el cuestionario es para analizar la relación establecida con el territorio a partir de la participación en el proyecto sociocultural comunitario. La Tabla 7 evidencia la correlación entre todos los ítems de esta categoría. Entre las más representativas se encuentra la establecida entre el I17 y el I11 $(\rho=, 559)$ que evidencia una relación entre el sentimiento de pertenencia aumentado con la participación en el proyecto sociocultural y la importancia de que el barrio sea un referente cultural en el territorio. Igualmente, en estas relaciones, emerge cómo las actividades culturales afectan positivamente el barrio y con ella su sentimiento de pertenencia. La fiabilidad entre los ítems de esta dimensión es aceptable con el valor de 0,696.

Tabla 7 - Correlación de Pearson de la dimensión anclaje territorial

\begin{tabular}{|c|c|c|c|c|c|}
\hline \multicolumn{6}{|c|}{ Anclaje territorial } \\
\hline \multicolumn{6}{|c|}{ Correlaciones } \\
\hline & & P5 & P11 & P17 & P21 \\
\hline \multirow[t]{3}{*}{ I5 } & Correlación de Pearson & 1 &, $449 * *$ & $453^{* *}$ &, $178^{* *}$ \\
\hline & Sig. (bilateral) & & 0,000 & 0,000 & 0,000 \\
\hline & $\mathrm{N}$ & 268 & 268 & 268 & 268 \\
\hline \multirow[t]{3}{*}{ I11 } & Correlación de Pearson & $449 * *$ & 1 &, $559 * *$ &, $364^{* *}$ \\
\hline & Sig. (bilateral) & 0,000 & & 0,000 & 0,000 \\
\hline & $\mathrm{N}$ & 268 & 268 & 268 & 268 \\
\hline \multirow[t]{3}{*}{117} & Correlación de Pearson & $453^{* *}$ &, $559 * *$ & 1 &, $189 * *$ \\
\hline & Sig. (bilateral) & 0,000 & 0,000 & & 0,000 \\
\hline & $\mathrm{N}$ & 268 & 268 & 268 & 268 \\
\hline \multirow[t]{3}{*}{ I21 } & Correlación de Pearson &, $178^{* *}$ & $364^{* *}$ &, $189 * *$ & 1 \\
\hline & Sig. (bilateral) & 0,000 & 0,000 & 0,000 & \\
\hline & $\mathrm{N}$ & 268 & 268 & 268 & 268 \\
\hline
\end{tabular}

** La correlación es significativa en el nivel 0,01 (bilateral).

Fuente: Elaboración propia. 
Analizando las correlaciones fundamentales entre ítems de diferentes categorías, se constató el I11, que refiere: "participar en las actividades culturales aumentó mi sentimiento de pertenencia hacia mi barrio"; y fue el planteamiento con más altos niveles de correlación con ítems de otras categorías. Específicamente, se mostró que la satisfacción expresada a través de la experiencia estética (I1) y el sentirse bien participando (I7) están correlacionadas con el sentimiento de pertenencia al barrio. También resultó interesante la correlación entre el I4 el I24, con la cual se evidencia que la libertad de expresión y actuación pueden crear competencias para la mejor comprensión del otro. El I5 (siento que el arte es parte de mi) está correlacionado con la importancia para esta persona que su barrio sea un referente cultural. El cuestionario presenta alto nivel de correlación entre sus ítems y categorías, corroborando la pertinencia en la construcción de cada planteamiento con la comunalidad creada.

\section{Discusiones}

La escala para analizar las mediaciones culturales en proyectos socioculturales comunitarios supone una aportación en las ramas de estudio de la comunicación, los estudios culturales y el trabajo sociocultural comunitario. Este instrumento propone la sistematización de varias dimensiones de las mediaciones culturales que son estudiadas por casos particulares o por manifestaciones artísticas; sin embargo, en esta propuesta se agrupan en un solo cuestionario. En el marco de las dinámicas sociales actuales para los proyectos socioculturales comunitarios, constituye un instrumento de análisis que sirve como termómetro de la realidad vivida por los participantes.

Los resultados obtenidos a través del análisis literario y grupos focales, el consenso de especialistas a través del método Delphi y las pruebas psicométricas validan las dimensiones propuestas para comprender las mediaciones culturales en el marco de un proyecto sociocultural comunitario. El AFE evidenció claramente la creación de cinco comunalidades y cómo la 
mayoría de los ítems propuestos coincidieron con la agrupación inicial. El AFC confirmó la correlación existente entre categorías, aunque en algunos casos con valores mínimos aceptables.

Las diferentes comunalidades planteadas desde la concepción del instrumento hasta las encontradas en los análisis factoriales, evidencian la presencia de un concepto que dista mucho de ser unidimensional. Sin embargo, más allá de proponer delimitaciones conceptuales a las diferentes subescalas que responden a las dimensiones anteriormente enunciadas, este instrumento apuesta por la compresión relacional entre cada una de ellas; otorgándole sentido al entramado de dispositivos de mediación cultural activados en un proyecto sociocultural comunitario.

Las dimensiones estuvieron relacionadas entre ellas coincidiendo con los resultados de otras investigaciones. La relación existente entre la dimensión experiencia estética y anclaje territorial es un ejemplo. Los autores Langeard, Liot y Rui (2015) mostraron que los proyectos socioculturales, en esta ocasión, de teatro, lograron con el tiempo nuevas formas de inscripción social convirtiendo el territorio en un espacio de públicos a participantes en una experiencia transformadora. Además, esta idea se fundamentó también por Grésillon (2008) y su concepto de geografía cultural. Según este autor, en los últimos tiempos emergieron experiencias socioculturales en lugares inesperados (fábricas abandonadas, zonas militares, almacenes abandonados, barrios periféricos), deviniendo en nuevos territorios para el desarrollo del arte y, por consecuencia, el desarrollo local. Con estos estudios, las dimensiones propuestas no solo se han validado en pruebas estadísticas, sino también con investigaciones en otros territorios.

Las correlaciones que se establecieron entre la dimensión axiológica y las demás, en su gran mayoría oscilaron en los límites permitidos. Sin embargo, no cabe duda de que las mediaciones adoptan diferentes niveles y formas de relación con el individuo y entre los propios individuos en la construcción de su personalidad. Colpé (2018) lo mostró a través del análisis de un proyecto sociocultural con adolescentes en el marco de Mons 2015 - capital europea de la cultura - y cómo la experiencia vivida en este 
proyecto fue moldeando ciertos valores en los participantes: capacidad de escucha, comprensión y pro-activismo.

Las cinco dimensiones propuestas para comprender las mediaciones culturales en un proyecto sociocultural se basaron en la idea propuesta por Martín-Barbero (1991), Orozco (1997) y Caune (2017) especialmente: las mediaciones culturales como aquellos dispositivos que se presentan en la creación de lazos sensibles en una colectividad. Nuestra pregunta de control tuvo como bases esas premisas, el 16 obtuvo una puntuación media de 5,94, indicando que los participantes están de acuerdo con que los proyectos posibilitan nuevas dinámicas de cohesión, participación y significados que reconfiguran su vida diaria. Sin embargo, es importante señalar que se encontraron respuestas entre el punto mínimo y máximo posible a responder. No obstante, estas dinámicas pueden ser traducidas a los procesos de mediación cultural en cual se observan fenómenos de hibridación entre las dimensiones estéticas, sociales y subjetivas en contextos particulares, tesis defendida por Fevry y Vanneste (2018). La escala propuesta responde a esa idea de mediación cultural como dispositivo de interacción que brinda sentido a eso que hacemos o somos (Chabanne, 2018) y responde al Ilamado que realizan los investigadores de las ciencias sociales sobre la necesidad de crear nuevos instrumentos para comprender "eso" que el arte provoca en las comunidades.

\section{Conclusiones}

En los proyectos socioculturales comunitarios, los dispositivos de mediación cultural permiten promover la creación y aumentar la visibilidad de las producciones culturales y artísticas. Las mediaciones culturales pueden ser conscientes e intencionales en los proyectos socioculturales de la comunidad y responder a objetivos de desarrollo. Es por ello que, en las actividades artísticas organizadas en el marco de un proyecto sociocultural, se puede mejorar la experiencia estética en torno a una obra; se abre el diálogo, la reflexión y el entendimiento colectivo de un acto cultural, lo 
que permite un mayor conocimiento dentro de la comunidad como fuera de ella.

Hablar de desarrollo cultural de la ciudad es pensar no solo en los centros culturales reconocidos dentro del territorio, sino también en zonas sociogeográficas complejas. Este hecho es relevante porque la mediación cultural, intencional o espontánea, sin importar el actor social que la genere, puede revitalizar entornos completamente marginados y olvidados, incluso por las instituciones públicas responsables políticamente.

La escala propuesta es la evidencia de un proceso de triangulación de varias técnicas y métodos para alcanzar una mayor confiabilidad y validez en el instrumento. Aunque las pruebas psicométricas muestran resultados robustos y significativos, se recomienda su aplicación en otros contextos socioculturales para así conocer si el agrupamiento factorial se mantiene o aparecen nuevas comunalidades. La presencia de estas iniciativas socioculturales locales es cada vez más frecuente en los países latinoamericanos, por lo que recomendamos investigaciones con un carácter holístico que permitan alcanzar una mirada más integral de los efectos producidos por los proyectos socioculturales comunitarios en los territorios de acción.

Elier González-Martínez es Master en Desarrollo y Sociedades, doctorando en Información y Comunicación de la Universidad Católica de Louvain la Neuve (Bélgica) y profesor titular auxiliar de la Universidad Politécnica Salesiana de Ecuador, Quito, Ecuador.

$\equiv$ egonzalez@ups.edu.ec

Belkis Rojas Hernández es Doctora en Ciencias Sociológicas en la Universidad de La Habana y profesora titular de la Universidad de Pinar del Río, Pinar del Río, Cuba.

ఏbelky1976@upr.edu.cu 


\section{Referencias}

1. AMADO, Ana. Arte participativo. El trabajo como (auto)representación. Significação - Revista de Cultura Audiovisual (USP, Brasil), v. 37, n. 34, p. 82-102, 2010. Disponible en: https://doi.org/10.11606/issn.2316-7114.sig.2010.68115

2. ARDENNE, Paul. L'art dans I'espace public: un activisme. Les Plumes, v. 5, n. 56, p. 1-24, 2011. Disponible en: http://edredon.uqam.ca/upload/files/ plumes/2011/Paul_Ardenne2.pdf

3. ASTIGARRAGA, Eneko. El método Delphi. (Material didáctico disponible en línea). Facultad de CC.EE. y Empresariales. ESTE, Universidad de Deusto (España), 2005. Disponible en: http://www.prospectiva.eu/zaharra/Metodo_delphi.pdf

4. BACA-TAVIRA, Norma; HERRERA-TAPIA, Francisco. Proyectos sociales. Notas sobre su diseño y gestión en territorios rurales. Convergencia. Revista de Ciencias Sociales, v. 23, n. 72, p. 69-87, 2016. Disponible en: http://www.scielo.org.mx/ scielo.php?script=sci_arttext\&pid=S1405-14352016000300069\&lng=es\&tlng= es

5. BANG, Claudia L. El arte participativo en el espacio público y la creación colectiva. Creatividad y Sociedad, n. 20, p. 1-25, 2013. Disponible en: http:// creatividadysociedad.com/wp-admin/Art\%C3\%ADculos/20/2.\%20El\%20arte\%20 participativo\%20en\%20el\%20espacio\%20publico.pdf?_t=1576011997

6. BANG, Claudia L.; WAJNERMAN, Carolina. Arte y transformación social: la importancia de la creación colectiva en intervenciones comunitarias. Revista Argentina de Psicología, n. 48, p. 89-103, 2010. Disponible en: http://www.psi. uba.ar/academica/carrerasdegrado/psicologia/sitios_catedras/obligatorias/066 salud2/material/publicaciones/arte_y_transformacion.pdf

7. CAUNE, Jean. La médiation culturelle: expérience esthétique et construction du vivre-ensemble. Grenoble: Presses Universitaires de Grenoble, 2017.

8. CAUNE, Jean. La démocratisation culturelle: une médiation à bout de souffle. Grenoble: Presses Universitaires de Grenoble, 2010.

9. CHABANNE, Jean-Charles. Jean Caune, La médiation culturelle. Expérience esthétique et construction du vivre-ensemble. Questions de Communication, n. 33, p. 355-357, 2018.

10. CHAUMIER, Serge; MAIRESSE, François. La médiation culturelle. Paris: Armand Collin, 2013.

11. CHEN, Guo-Ming; STAROSTA, William. The development and validation of the intercultural communication sensitivity scale. Human Communication, v. 3, p. 1-15, 2000.

12. COLIGNON, Martine. Art-thérapie, médiations artistiques: quelles différences pour quels enjeux? (Entretien avec Jean-Marc L. Delabarre). La nouvelle revue de I'adaptation et de la scolarisation, v. 72, n. 4, p. 295-315, 2015. https://doi. org/10.3917/nras.072.0295 
13. COLPÉ, Chloé. La fabrique des héros: une étude sur vingt adolescents dans le sillage de Wajdi Mouawad. Les Politiques Sociales: art, médiation culturelle et territoires, n. 3-4, p. 25-36, 2018.

14. ELOY, Jacques. L'apport du socioculturel à la cohésion sociale au regard de la longue histoire des centres sociaux. Informations sociales, v. 190, n. 4, p. 37-45, 2015. https://doi.org/10.3917/inso.190.0037

15. ESPINOSA-DÍAZ, Yessica; LLORÉNS-BÁEZ, Luis. Exploración de la capacidad de liderazgo para la incorporación de TICC en educación: validación de un instrumento. Revista Latinoamericana de Tecnología Educativa, v. 14, n. 3, p. 35-47, 2015. https://doi.org/10.17398/1695-288X.14.3.35

16. FEVRY, Sébastien; VANNESTE, Damien. Présentation: Art, médiation culturelle et territoires. Les Politiques Sociales, n. 3-4, p. 3-11, 2018.

17. GRÉSILLON, Boris. Ville et création artistique. Pour une autre approche de la géographie culturelle. Annales de Géographie, v. 660-661, n. 2, p. 179-198, 2008. https://doi.org/10.3917/ag.660.0179

18. HAMMER, Mitchell; BENNETT, Milton; WISEMAN, Richard. Measuring intercultural sensitivity: the intercultural development inventory. International Journal of Intercultural Relations, v. 27, n. 4, p. 421-443, 2003. https://doi. org/10.1016/S0147-1767(03)00032-4

19. HERNÁNDEZ-BELVER, Manuel; MARTÍN-PRADA, Juan L. La recepción de la obra de arte y la participación del espectador en las propuestas artísticas contemporáneas. Reis - Revista Española de Investigaciones Sociológicas, v. 84, p. 45-63, 1998. Disponible en: http://www.jstor.org/stable/40184076.

20. JACOB, Louis; BÉLANGER, Anouk. Les effets de la médiation culturelle: participation, expression, changement. Rapport final. Étude partenariale réalisée a Montréal de 2011 à 2013. Montreal: UQÀM, 2014. Disponible en: < http:// montreal.mediationculturelle.org/etudes-et-recherches/>.

21. JOUËT, Josiane. Pratiques de communication et figures de la médiation. Réseaux, v. 60, n. 4, p. 99-120, 1993. Disponible en: https://www.cairn.info/ revue-reseaux1-1993-4-page-99.htm.

22. LAMIZET, Bernard. Le passeur, éthique du sens, médiation culturelle. Reseña de «Pour une éthique de la médiation: le sens de pratiques culturelles », de Jean Caune (1999). Réseaux, v. 18, n. 101, p. 197-201, 2000.

23. LANGEARD, Chloé; LIOT, Françoise; RUI, Sandrine. Ce que le théâtre fait au territoire. Reconfiguration du public et évaluation. Espaces et Sociétés, v. 163, n. 4, p. 107-123, 2015. https://doi.org/10.3917/esp.163.0107

24. LOSER, Francis. La médiation artistique en travail social. Enjeux et pratiques en atelier d'expression et de création. Ginebra: Éditions IES, 2010.

25. MARTíN-BARBERO, Jesús. De los medios a las mediaciones. Comunicación, cultura y hegemonía. Barcelona, España: Gustavo Gili, 1991. 
26. MARTY, Gisèle et al. Dimensiones factoriales de la experiencia estética. Psicothema, v. 15, n. 3, p. 478-483, 2003. Disponible en: http://www. psicothema.es/pdf/1091.pdf

27. MEJÍA-ARAUZ, Rebeca. Combinación estratégica: investigación sociocultural cualitativa-cuantitativa. Nómadas, n. 18, p. 20-27, 2003.

28. MYSZKOWSKI, Nils; ZENASNI, Franck. Individual differences in aesthetic ability: the case for an aesthetic quotient. Frontier in Psycology, v. 7, p. 1-5, 2016. https://doi.org/10.3389/fpsyg.2016.00750

29. OÑATE-MARTÍNEZ, Norma; RAMOS-MORALES, Lázaro; DÍAZ-ARMESTO, Abilio. Utilización del Método Delphi en la pronosticación: una experiencia inicial. Economía Planificada, v. 3, n. 4, p. 9-48, JUCEPLAN, La Habana, Cuba, 1988.

30. OROZCO, Guillermo. Medios, audiencias y mediaciones. Comunicar, n. 8, p. 25-30, 1997. Disponible en: https://www.redalyc.org/articulo.oa?id=15800806

31. PRICKETT, Kate; ANGEL, Jacqueline. Métodos empíricos em pesquisa do envelhecimento entre minorias: um caso para triangulação sociológica. Sociologias, v. 14, n. 31, p. 146-165, 2012. http://dx.doi.org/10.1590/S151745222012000300007

32. RAMÍREZ, Ma. Carmen.; RUIZ, José-Antonio.; TORRENTE, Ginesa; RODRÍGUEZ, Ángel. Desarrollo de una escala de estrés de aculturación en autóctonos. Revista de Psicología Social: International Journal of Social Psychology, v. 27, n. 1, p. 55-67, 2014. https://doi.org/10.1174/021347412798844024

33. RASSE, Paul. La médiation entre idéal théorique et application pratique. Recherche en Communication, n. 13, p. 38-61, 2000.

34. RAYCHAUDHURI, Manas. Algunos correlatos perceptivos de la sensibilidad estética. Revista Latinoamericana de Psicología, v. 4, n. 2, p. 221-226, 1972. Disponible en: https://www.redalyc.org/articulo.oa?id=80540205

35. ROSALES-GONZÁLEZ, Margarita. Estrategias de intervención para el desarrollo local. Experiencias en comunidades mayas del sur de Yucatán. Península, v. 7, n. 1, p. 79-102, 2012. Disponible en: http://www.revistas.unam.mx/index.php/ peninsula/article/view/44463

36. SAURIER, Delphine; GHLAMALLAH, Sarah. Souplesse et permanence de la médiation culturelle. Le cas de la visite découverte du musée du Louvre. Questions de Communication, n. 28, p. 251-272, 2015. Disponible en: http:// journals.openedition.org/questionsdecommunication/10124

37. SCIEUR, Philippe; VANNESTE, Damien. La médiation artistique et culturelle: cadrage théorique et approche sociologique. Repères, v. 6, p. 5-32, 2015. Disponible en: http://hdl.handle.net/2268/223655

38. SMITH-CASTRO, Vanessa. La Escala de Identidad Étnica Multigrupo (EIEM) en el contexto costarricense. Actualidades en Psicología, v. 18, n. 105, p. 47-67, 2002. https://doi.org/10.15517/ap.v18i105.54 
39. UNESCO. Cómo medir la participación cultural. Manual del marco de estadísticas culturales de la UNESCO 2009 no2. Montreal: Instituto de Estadística de la UNESCO, 2014a.

40. UNESCO. Indicadores UNESCO de cultura para el desarrollo. Manual metodológico. Paris: UNESCO, 2014b. 


\section{Apéndice}

\section{Escala de mediaciones culturales en el contexto de proyectos} socioculturales comunitarios

1- Edad

2- Sexo

3- Seleccione el tiempo que usted ha sido participante activo del proyecto sociocultural comunitario:

$\square$ Entre seis meses y un año

$\square$ Entre uno y dos años

$\square$ Entre tres y cinco años

Más de cinco años

4- Seleccione cuál de las manifestaciones culturales usted desarrolla en el proyecto sociocultural (puede escoger hasta las dos más importantes)

$\square$ Literatura

$\square$ Danza

$\square$ Música

$\square$ Artes plásticas

Teatro

5- El proyecto sociocultural comunitario se desarrolla directamente en la zona donde vives:

$\mathrm{Si}$

No 
Tabla 8: Cuestionario

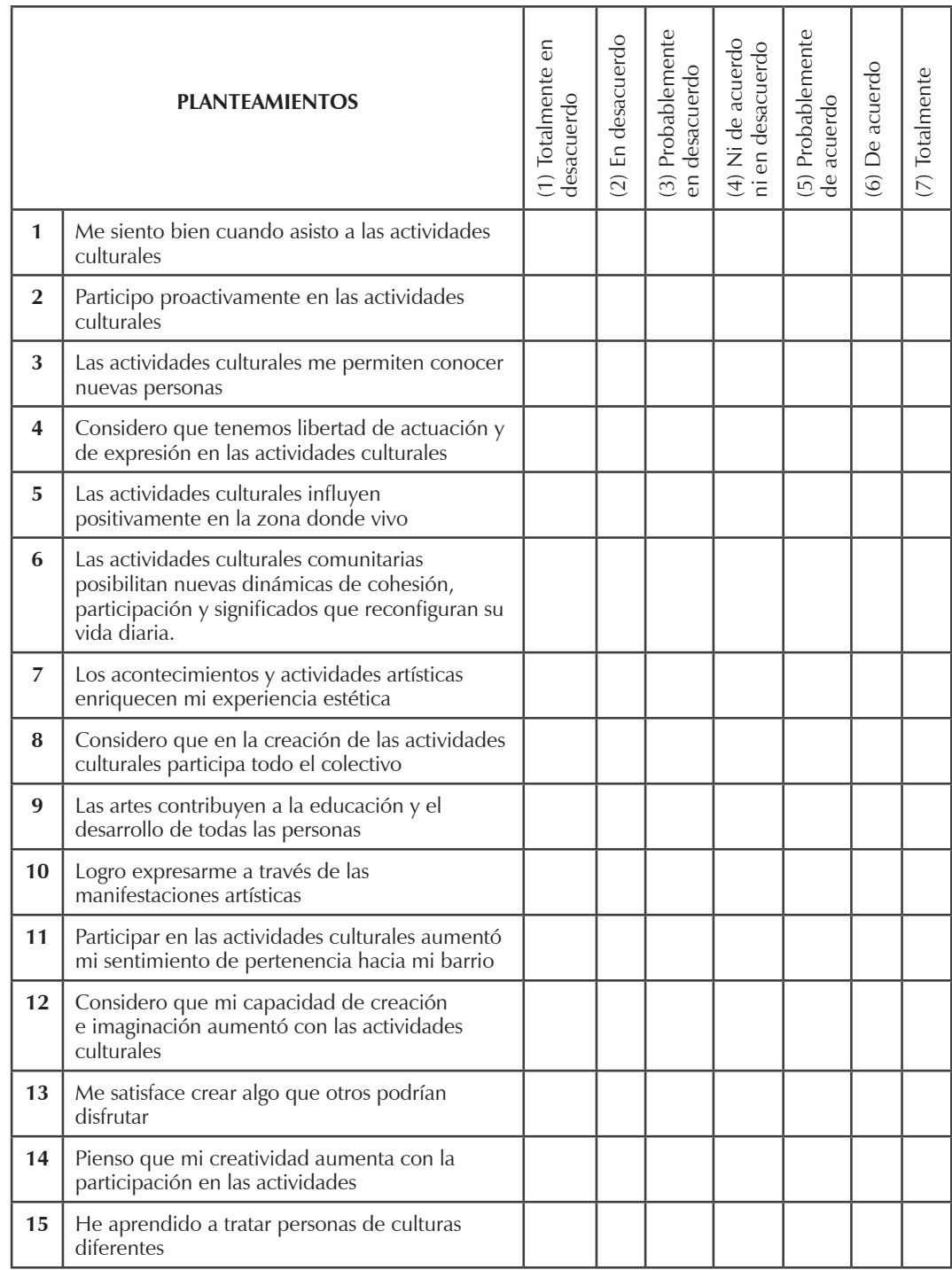


(cont.)

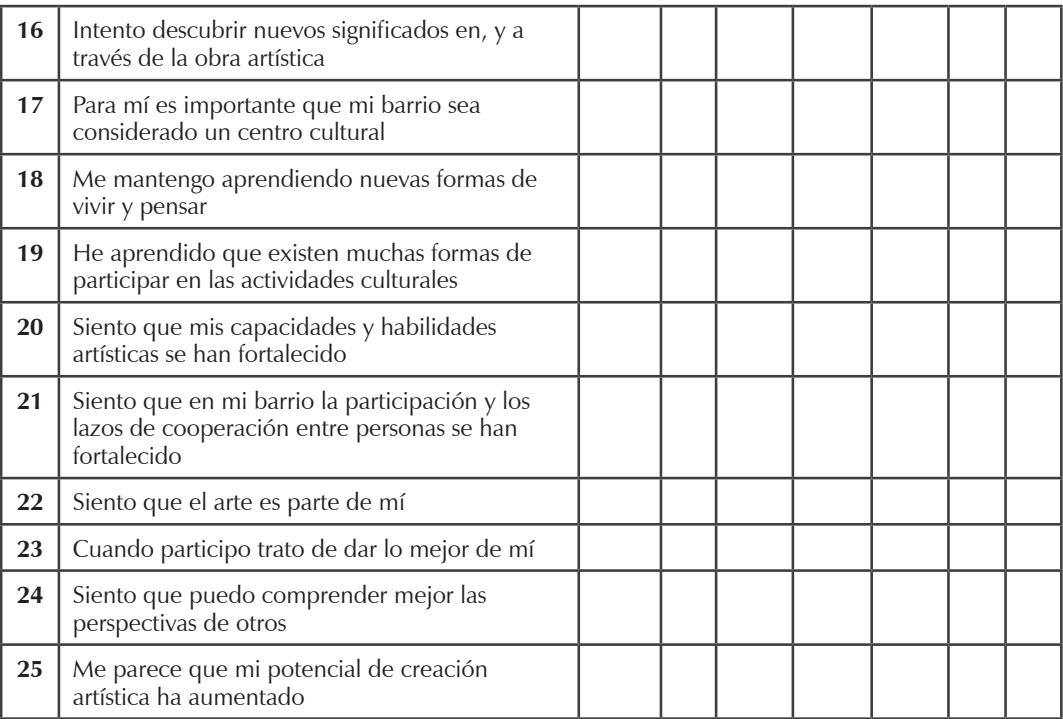

Recibido: 24 mar. 2019.

Aceptado: 10 sept. 2019.

Sociologias, Porto Alegre, ano 22, n. 53, jan-abr 2020, p. 194-227. 